\title{
Avaliação da competitividade da agricultura do Alentejo no âmbito do ecossistema Montado'
}

\author{
Rui Fragoso ${ }^{2}$ \\ Raquel Lucas $^{3}$
}

Resumo: Neste estudo procede-se à avaliação sócioeconómica do ecossistema montado no Alentejo, em termos da viabilidade dos actuais sistemas de produção e dos efeitos da política agrícola na sua competitividade e sustentabilidade. A metodologia utilizada baseou-se na construção de matrizes de análise política. Em função dos níveis de rendimento e dos efeitos das medidas de política agrícola, os sistemas de produção são classificados em termos da sua contribuição real para o crescimento económico.

Palavras-chaves: Montado, Alentejo, Matriz de Análise Política, competitividade, Política Agrícola Comum.

Classificação JEL: Q11, Q12, Q18

${ }^{1}$ Trata-se de um artigo cujo autores são de Portugal. Dessa forma, o artigo está escrito em português corrente utilizado em Portugal, em que não há correspondência de termos com o português utilizado no Brasil, mesmo para textos científicos em economia.

2 Professor Auxiliar do Departamento de Gestão e membro do Instituto de Ciências Agrárias Mediterrânico, Universidade de Évora, Portugal. E-mail: rfragoso@uevora.pt

${ }^{3}$ Professora Associada com Agregação do Departamento de Gestão e Membro do Centro de Estudos e Formação Avançada em Gestão e Economia, Universidade de Évora, Portugal. E-mail: mrlucas@uevora.pt 
Abstract: This paper makes a socio-economic evaluation of the "Montado" ecosystem in Alentejo. It is study the viability of the agricultural systems and the effects of agricultural policy in their competitiveness and sustainability. It is used a Policy Analysis Matrix to evaluate the agricultural systems competitiveness and their economic efficiency. The agricultural systems are classified concerning their contribution for the economic growth, in function of income levels and policy effects.

Key-words: "Montado", Alentejo, Policy Analysis Matrix; competitiveness, Common Agricultural Policy.

JEL classification: Q11, Q12, Q18

\section{Introdução}

A Região Alentejo, localizada no Sul de Portugal entre o Rio Tejo e a Região Algarve, representa cerca de um terço do território português e apenas cerca de $5 \%$ da população. A sua situação sócioeconómica é mais desfavorável do que a média de Portugal e tende a acentuar-se (Figura 1). Em 2001, o Produto Interno Bruto (PIB) per capita no Alentejo traduzia num nível de vida da população alentejana cerca de $20 \%$ abaixo da média do país e o Rendimento Bruto Disponível das Famílias (RBDF) era inferior em cerca de $13 \%$. Nas últimas décadas, a população do Alentejo tem registado uma evolução negativa e apresenta a densidade populacional mais baixa no país e um índice de envelhecimento $(173,4)$ substancialmente superior ao índice de envelhecimento nacional $(102,2)$. Face a esses indicadores, seria de esperar uma taxa de actividade económica (TAE) inferior à média nacional (em cerca de $3 \%$ ) e uma taxa de desemprego mais elevada (em cerca de $2 \%$ ).

Figura 1. Indicadores socio-económicos em Portugal e no Alentejo

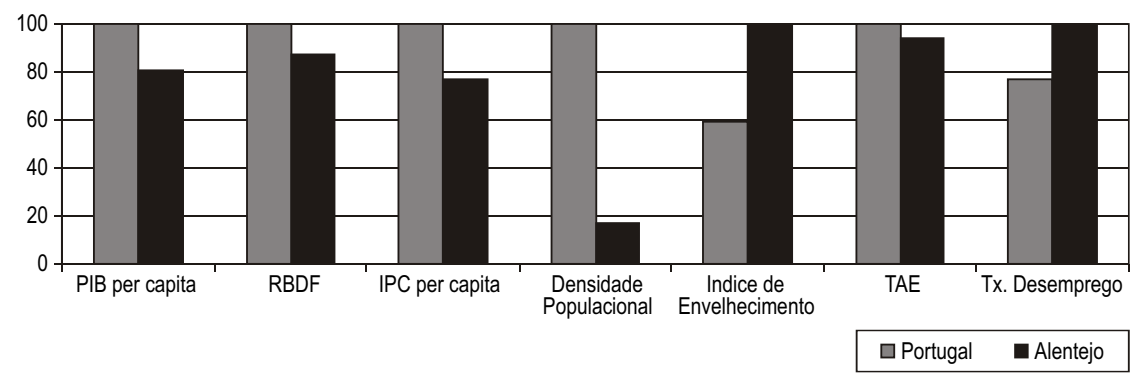

Fonte: Lucas et al, 2005 
A análise do Valor Acrescentado Bruto (VAB) permite concluir que, em 2001, o sector primário representava 16,4\% da economia do Alentejo. Este contributo, quase exclusivo da agricultura, da silvicultura e da caça, é cerca de quatro vezes superior ao do sector primário no VAB nacional. Na população empregada por sector de actividade económica, embora se verifique a predominância de actividades associadas ao sector terciário (61\% de emprego), a população empregada no sector primário (13\% do emprego) representa quase o triplo da média de Portugal (Lucas et al., 2005).

Esses indicadores demonstram, de um modo geral, uma forte especialização do Alentejo nas actividades relacionadas à agricultura, à silvicultura e à caça, à qual não é alheia a existência do ecossistema montado, que abrange toda a Região de uma forma muito significativa. Segundo os dados do Recenseamento Geral Agrícola de 1999 (INE, 1999), cerca de $43 \%$ da superfície total das explorações agrícolas alentejanas é ocupada por matas e florestas, que no Alentejo são maioritariamente montado de sobro ou montando de azinho. Cerca de $80 \%$ dessa área de matas e florestas é aproveitada com culturas ou pastagens sob-coberto, facto que permite identificar o inegável interesse sócioeconómico da exploração agro-florestal do ecossistema montado na Região.

No ecossistema montado, para além das actividades agroflorestais, desenvolvem-se a montante e a jusante diversas actividades económicas associadas ao meio rural. Importa ainda referir que o montado é um ecossistema altamente vulnerável, no qual para além da fauna e flora associadas, nas quais existem espécies que correm riscos de extinção, existem áreas onde os riscos de erosão são bastantes elevados, não só devido às cargas animais elevadas como também à intensificação cultural e à utilização de determinadas práticas culturais.

Para o desenvolvimento sustentado do ecossistema montado, tornou-se imprescindível estudar, desenvolver e difundir modelos e tecnologias adequados à resolução dos problemas que enfrentam os seus actores (administração pública, associações de produtores, proprietários rurais e outros).

Este estudo trata o problema dos rendimentos agrícolas no âmbito da gestão sustentável do ecossistema montado na Região Alentejo, nomeadamente no que diz respeito à competitividade e viabilidade económica dos seus sistemas de produção agroflorestal representativos 
no contexto actual e das perspectivas futuras da Política Agrícola Comum (PAC). Deste modo, pretende-se responder às seguintes questões:

i) Quais os níveis de competitividade decorrentes das especificidades agroecológicas do ecossistema montado no contexto da PAC?

ii) Quais os efeitos das transferências institucionais de rendimento preconizadas no âmbito da PAC e em especial no que diz respeito ao seu segundo pilar relativo à política de desenvolvimento rural?

Sendo a informação disponível insuficiente para realizar de forma eficaz a gestão integrada dos recursos do ecossistema montado no Alentejo, este artigo pretende realizar a sua avaliação sócioeconómica, em termos da viabilidade dos actuais sistemas de produção e dos efeitos da política agrícola na sua competitividade e sustentabilidade e contribuir para fornecer informação de âmbito sócioeconómico para a tomada de decisões e para a definição das políticas adequadas.

Além desta introdução, este o artigo compreende mais três secções, referentes à metodologia, aos resultados e às conclusões.

\section{Metodologia}

Os sistemas de produção do ecossistema montado, por encerrarem um conjunto de especificidades e de aspectos complementares da produção agroflorestal, devem ser analisados no contexto microeconómico da unidade de produção.

$\mathrm{Na}$ análise económica, destaca-se a utilização do método dos orçamentos, de modelos econométricos cujas aplicações ao tema da competitividade podem ser seguidos em Mattas (1990) e Bureau e Butuault (1990) para a agricultura comunitária e em Maza et al (1992) para a produção ovina, de modelos de programação matemática (Jaraba et Thompson, 1980; Baysan, 1984; Martin, 1989; Abreu, 1987; Marques, 1988, Marques et al, 1995; e Lucas, 1995) e de matrizes de análise de política (Pearson et Meyer, 1974; Santana, 1986; Fox, 1987; Pearson et al, 1987; Avillez et Queiroz, 1987; Avillez et al. 1988; Pearson et Monke, 1989; e Venturini, 1989).

A matriz de análise de política (Policy Analysis Matrix - PAM) proposta por Pearson e Meyer em 1974, tem sido frequentemente utilizada na análise da competitividade agrícola, devido à facilidade de integrar cronologicamente os aspectos tecnológicos da produção 
agroflorestal, a procura de factores e a oferta de produtos. Por essas razões, a PAM foi a metodologia adoptada para avaliar a competitividade dos Sistemas de Produção Agro-Florestal do Montado (SPAM) e o seu contributo eficiente para o crescimento da economia, assim como as transferências institucionais de rendimento das políticas económicas em vigor, nomeadamente da PAC e das políticas nacionais de apoio ao sector agroflorestal e ao desenvolvimento rural.

Basicamente esta metodologia consiste em construir para cada SPAM matrizes de custos, de proveitos e de resultados, primeiro incluindo os efeitos das políticas económicas e depois sem o efeito dessas políticas. Na Tabela 1, apresenta-se a estrutura simplificada da PAM utilizada.

Tabela 1. Matriz de Análise Política

\begin{tabular}{|c|c|c|c|c|}
\hline Análise & Proveitos & Custos & $\mathbf{R L}$ & $\mathbf{R} \mathbf{L}^{(*)}$ \\
\hline Preços privados & A ou $A^{\prime}$ & B & $\mathrm{C}$ & $\mathrm{D}$ \\
\hline Preços sociais & E & $\mathrm{F}$ & G & G \\
\hline Efeitos de política e falhas de mercado & $\mathrm{H}$ & I & $\mathrm{J}$ & $\mathrm{L}$ \\
\hline
\end{tabular}

A coluna da PAM correspondente ao Resultado Líquido (RL) traduz o balanço entre os proveitos e os custos. Este balanço pode ser efectuado a preços privados e a preços sociais e em termos das transferências líquidas institucionais de rendimento.

O RL a preços privados (C ou D) é dado pela primeira linha da matriz, subtraindo os custos a preços de mercado (B) dos proveitos a preços de mercado (A). $\mathrm{O}$ resultado obtido pelo elemento $\mathrm{C}$ da matriz mostra como os SPAM reagem aos efeitos das políticas de transferência de rendimento decorrentes da PAC. Este resultado permite avaliar o RL a preços privados no contexto sócioeconómico em vigor. $\mathrm{O}$ elemento $\mathrm{D}$ da matriz avalia isoladamente os efeitos nos SPAM das políticas de desenvolvimento rural inseridas no segundo pilar da PAC.

O RL a preços privados representa o Rendimento Empresarial Líquido por unidade de superfície utilizada, ou seja, a retribuição dos factores próprios terra, capital e empresário. Um RL positivo a preços privados, indica que o SPAM gera proveitos suficientes para cobrir os custos reais dos factores de produção no contexto sócioeconómico em que se insere. 
O RL a preços sociais $(G)$ é dado pela segunda linha da matriz, subtraindo os custos a preços sociais $(\mathrm{F})$ aos proveitos a preços sociais (E). $\mathrm{O}$ resultado obtido mostra a rentabilidade dos SPAM num contexto de economia aberta sem os efeitos das transferências de rendimento da PAC e das políticas nacionais apoio ao sector. Neste caso, um RL positivo indica que o conjunto das actividades agroflorestais levadas a cabo no SPAM são eficientes do ponto de vista económico, na medida em que permitem a sua rentabilidade mesmo num contexto de preços livres sem as transferências de rendimento preconizadas pelas políticas públicas.

$\mathrm{Na}$ PAM a diferença entre a primeira linha a preços privados e a segunda linha a preços sociais traduz os efeitos das políticas institucionais de transferência de rendimento e eventuais falhas de mercado. Os apoios públicos à produção, ao rendimento e ao desenvolvimento rural são dados pelo elemento $\mathrm{H}$ da PAM, que é obtido da diferença entre A e E. Se o seu valor for positivo, os proveitos a preços privados (A) excedem os proveitos a preços sociais (E). Nesta situação, a produção e o rendimento são apoiados institucionalmente, devido aos preços internos serem superiores aos de importação por falta de competitividade da produção interna ou por seram pagas ajudas por serviços prestados à comunidade, como é caso das ajudas inseridas no segundo pilar da PAC.

Os apoios públicos à utilização de factores são dados pelo elemento I da PAM, resultante da diferença entre B e F, que são, respectivamente, o custo dos factores a preços privados e o custo dos factores a preços sociais. Um valor positivo de I revela a existência de subsídios para tornar a produção agroflorestal mais competitiva, por os preços internos dos factores de produção serem superiores aos do mercado internacional ou dos factores domésticos terem custos de oportunidade demasiado elevados.

Os efeitos líquidos de todas as políticas institucionais de transferência de rendimento em vigor (J) é o resultado da diferença entre todas as políticas de apoio à produção, ao rendimento e ao desenvolvimento rural $(\mathrm{H})$ e as políticas de apoio à utilização de factores (I). O elemento L da PAM traduz o efeito líquido da política de desenvolvimento rural inserira no segundo pilar da PAC. Os efeitos líquidos das políticas públicas de transferência de rendimento também podem ser calculados, fazendo a diferença entre o RL a preços privado (C e D) e o RL a preços sociais $(G)$.

A avaliação dos resultados na óptica social requer que os proveitos e os custos sejam valorizados a preços de escassez, i.e., ao seu custo de oportunidade. Esta análise parte do pressuposto de que se os preços 
sociais forem considerados nas decisões económicas, se obtém uma afectação óptima dos recursos e, por conseguinte, um contributo eficiente do sector ou da actividade em causa para o crescimento económico.

No entanto, o problema da análise social reside exactamente no cálculo dos preços sociais, que não são mais do que os preços sombra dos recursos. Na impossibilidade de se dispor dos preços sombra, podem sempre utilizar-se aproximações aos preços sociais. Um exemplo muito frequente de aproximação aos preços sociais é a utilização dos preços internacionais CIF (cost, insurance and freight) para os produtos agrícolas indiferenciados e de preços internacionais FOB (free on board) para os factores de produção transaccionáveis no mercado internacional.

Os preços internacionais CIF e FOB não são passíveis de aplicação aos SPAM, visto que alguns dos produtos produzidos são exclusivos do ecossistema montado e apresentam alguma diferenciação, como é o caso da exploração de suínos da Raça Alentejana, em que não existe um preço no mercado internacional. $O$ facto de a economia portuguesa ser aberta ao exterior, também faz com que os preços do mercado interno sejam fortemente influenciados pelas importações. Deste modo, os preços nacionais dos produtos agrícolas e dos factores de produção transaccionáveis, relativamente aos preços dos países de origem, são influenciados apenas pelos custos de transporte e pelas margens de comercialização. Por essa razão, considerou-se para os preços sociais dos produtos agrícolas e dos factores de produção transaccionáveis, os respectivos preços no mercado nacional deduzidos das margens de comercialização.

A valorização a preços sociais dos factores domésticos, que não são transaccionáveis no mercado internacional, como é caso dos factores primários, terra, capital e mão-de-obra, requer uma abordagem distinta dos factores transaccionáveis. Estes factores devem ser avaliados pelo seu custo de oportunidade, que reflecte o rendimento que proporciona uma unidade do factor na sua melhor afectação alternativa.

É necessário diferenciar o factor terra dos restantes factores. No longo prazo, quando todos os factores são variáveis, a terra é o único factor que permanece fixo. Para o preço social da terra deve-se considerar o seu custo de oportunidade, que é dado pelo rendimento da melhor alternativa de produção agroflorestal. Quando não é possível determinar qual é a melhor alternativa agroflorestal ou quando existem enviusamentos que condicionam o cálculo do seu custo social, pode utilizar-se em alternativa 
o valor do mercado de arrendamento. Foi esta a opção tomada para a valorização da terra a preços sociais.

O custo social do capital fundiário benfeitorias e do capital fixo de exploração foi avaliado pelas taxas de remuneração dos capitais investidos, considerando-se uma taxa média anual de $2 \%$. Esta taxa reflecte uma retribuição média do capital idêntica às taxas de remuneração de grande parte das aplicações financeiras sem risco, situando-se ligeiramente acima da taxa de juro líquida dos depósitos a prazo e ligeiramente abaixo da taxa de inflação.

O capital circulante, por dispor de uma maior liquidez, é valorizado a uma taxa de juro superior à dos capitais fixos, considerando-se neste caso uma taxa de juro anual de $4 \%$, que resulta da aproximação à média aritmética das taxas anuais de juro dos depósitos a prazo e dos empréstimos de campanha.

No caso da mão-de-obra, o custo social é dado pelos indicadores médios de remuneração do trabalho no sector, obtidos a partir dos dados dos inquéritos, e tem também em conta o custo de oportunidade da mão-de-obra não remunerada.

Na PAM não se tem em conta as falhas de mercado, por se considerar que são pouco significativas e que em grande parte estão corrigidas pelas políticas públicas. Este pressuposto permite estabelecer uma relação directa entre os benefícios sociais e os efeitos de distorção das políticas de transferência institucional de rendimento.

\section{Resultados}

Numa primeira fase foram identificados, pela equipa da Unidade de Macroecologia \& Conservação da Universidade de Évora, os SPAM representativos no Alentejo, com base nos padrões dominantes de uma amostra de conveniência de 30 explorações agroflorestais. O estudo foi realizado tendo em conta os factores agroecológicos, a orientação técnico económica decorrente da origem do valor da produção e do tipo de actividades agroflorestais levadas a cabo e aspectos da economia agrícola, como a dimensão económica dos SPAM, a superfície agroflorestal e o volume de trabalho anual. Os resultados permitiram identificar 6 SPAM representativos da actividade agro-florestal no Alentejo, que constituem o objecto de estudo deste trabalho, e cujas características se apresentam na Tabela 2 e na Tabela 3. 
Tabela 2. Representatividade dos SPAM em termos de explorações agroflorestais e da superfície agrícola total

\begin{tabular}{ccc}
\hline SPAM & Número de explorações (\%) & Superfície Agrícola Total (\%) \\
\hline A & 16,7 & 20,5 \\
B & 26,7 & 31,8 \\
C & 13,3 & 6,8 \\
D & 23,3 & 33,7 \\
E & 10,0 & 3,1 \\
F & 10,0 & 4,1 \\
\hline
\end{tabular}

Fonte: Análise k-means realizada pelo grupo da Unidade de Macroecologia \& Conservação da Universidade de Évora.

Tabela 3. Sistemas de Produção Agroflorestal do Montado (SPAM) representativos no Alentejo

\begin{tabular}{|c|c|c|c|c|c|}
\hline SPAM & $\begin{array}{c}\text { Ocupação } \\
\text { do solo }\end{array}$ & $\begin{array}{l}\text { Actividad } \\
\text { e pecuária }\end{array}$ & $\begin{array}{l}\text { Característica } \\
\text { s da floresta }\end{array}$ & $\begin{array}{c}\text { Factores } \\
\text { climatológicos }\end{array}$ & $\begin{array}{c}\text { Aspectos de } \\
\text { economia } \\
\text { Agrícola } \\
\end{array}$ \\
\hline A & $\begin{array}{l}\text { Sistemas de } \\
\text { sob-coberto de } \\
\text { pastagens }\end{array}$ & $\begin{array}{l}\text { Bovinos e } \\
\text { suínos }\end{array}$ & $\begin{array}{c}\text { Fraco } \\
\text { florestal } \\
\text { predominant } \\
\text { e de azinho }\end{array}$ & $\begin{array}{c}\text { Zonas interiores, } \\
\text { com baixa } \\
\text { precipitação }\end{array}$ & $\begin{array}{c}\text { Grandes } \\
\text { explorações: } \\
1366 \text { ha de } \\
\text { SAU e } 6 \text { UTA }\end{array}$ \\
\hline B & $\begin{array}{l}\text { Sistemas de } \\
\text { forragens e } \\
\text { pastagens em } \\
\text { sob-coberto e em } \\
\text { terra limpa }\end{array}$ & Bovinos & Azinho denso & $\begin{array}{c}\text { Zonas interiores } \\
\text { com baixa } \\
\text { precipitação }\end{array}$ & $\begin{array}{l}\text { Médias e } \\
\text { pequenas } \\
\text { explorações: } \\
377 \text { ha de SAU } \\
\text { e } 2,42 \text { UTA }\end{array}$ \\
\hline $\mathrm{C}$ & $\begin{array}{l}\text { Sistemas de vinha } \\
\text { e olival e forragens } \\
\text { e pastagens }\end{array}$ & $\begin{array}{c}\text { Bovinos e } \\
\text { ovinos }\end{array}$ & $\begin{array}{c}\text { Azinho e } \\
\text { sobro denso }\end{array}$ & $\begin{array}{l}\text { Zonas litorais } \\
\text { com boas } \\
\text { precipitações }\end{array}$ & $\begin{array}{c}\text { Pequenas } \\
\text { explorações: } \\
177 \text { ha de SAU } \\
\text { e } 6,43 \text { UTA }\end{array}$ \\
\hline $\mathrm{D}$ & $\begin{array}{l}\text { Sistemas de } \\
\text { forragens e } \\
\text { pastagens } \\
\text { sob-coberto e em } \\
\text { terra limpa }\end{array}$ & $\begin{array}{l}\text { Bovinos e } \\
\text { suínos }\end{array}$ & $\begin{array}{l}\text { Azinho } \\
\text { disperso }\end{array}$ & $\begin{array}{c}\text { Zonas elevadas } \\
\text { no interior com } \\
\text { bons níveis de } \\
\text { precipitação }\end{array}$ & $\begin{array}{c}\text { Médias a } \\
\text { grandes } \\
\text { explorações: } \\
798 \text { ha de SAU } \\
\text { e 4,21 UTA }\end{array}$ \\
\hline E & $\begin{array}{l}\text { Sistemas de cereais } \\
\text { e pastagens } \\
\text { sob-coberto e em } \\
\text { terra limpa }\end{array}$ & Bovinos & $\begin{array}{c}\text { Muito sobro } \\
\text { denso }\end{array}$ & $\begin{array}{l}\text { Zonas interiores } \\
\text { próximas do } \\
\text { litoral com boas } \\
\text { precipitações no } \\
\text { Inverno }\end{array}$ & $\begin{array}{c}\text { Pequenas } \\
\text { explorações: } \\
\text { 107 ha de SAU } \\
\text { e } 1,15 \text { UTA }\end{array}$ \\
\hline $\mathrm{F}$ & $\begin{array}{l}\text { Sistemas de cereais } \\
\text { e pastagens } \\
\text { sob-coberto e em } \\
\text { terra limpa }\end{array}$ & Bovinos & $\begin{array}{c}\text { Sobro e } \\
\text { azinho denso }\end{array}$ & $\begin{array}{c}\text { Zonas interiores } \\
\text { com com Baixa } \\
\text { precipitação }\end{array}$ & $\begin{array}{c}\text { Pequenas a } \\
\text { médias } \\
\text { explorações: } \\
448 \text { ha de SAU } \\
\text { e 3,05 UTA }\end{array}$ \\
\hline
\end{tabular}

Fonte: Análise k-means realizada pelo grupo da Unidade de Macroecologia \& Conservação da Universidade de Évora 
Na Tabela 4, são apresentados os resultados das PAM para os SPAM representativos no Alentejo. A primeira coluna do Resultado Líquido inclui os efeitos das políticas actualmente em vigor contidas (primeiro e segundo pilar da PAC) e a segunda coluna do Resultado Líquido reflecte os efeitos isolados das políticas de desenvolvimento rural (segundo pilar da PAC).

Tabela 4. Resultados da Matriz de Análise Política para os SPAM

\begin{tabular}{|c|c|c|c|c|}
\hline & Proveitos & Custos & $\begin{array}{c}\text { Resultado } \\
\text { Líquido }\end{array}$ & $\begin{array}{l}\text { Resultado } \\
\text { Líquido (*) }\end{array}$ \\
\hline \multicolumn{5}{|c|}{ SPAM do tipo A } \\
\hline Preços privados & 192 & 125 & 67 & 16 \\
\hline Preços sociais & 123 & 167 & -43 & -43 \\
\hline Efeitos de política e falhas de mercado & 69 & -41 & 110 & 59 \\
\hline \multicolumn{5}{|c|}{ SPAM do tipo B } \\
\hline Preços privados & 899 & 311 & 589 & 216 \\
\hline Preços sociais & 511 & 411 & 100 & 100 \\
\hline Efeitos de política e falhas de mercado & 389 & -100 & 489 & 116 \\
\hline \multicolumn{5}{|c|}{ SPAM do tipo C } \\
\hline Preços privados & 1032 & 517 & 514 & 374 \\
\hline Preços sociais & 846 & 801 & 45 & 45 \\
\hline Efeitos de política e falhas de mercado & 185 & -283 & 469 & 329 \\
\hline \multicolumn{5}{|c|}{$\begin{array}{ll}\text { SPAM do tipo D } \\
\end{array}$} \\
\hline Preços privados & 279 & 199 & 79 & -50 \\
\hline Preços sociais & 140 & 268 & -128 & -128 \\
\hline Efeitos de política e falhas de mercado & 139 & -69 & 208 & 78 \\
\hline \multicolumn{5}{|c|}{ SPAM do tipo E } \\
\hline Preços privados & 613 & 411 & 202 & -195 \\
\hline Preços sociais & 202 & 502 & -300 & -300 \\
\hline Efeitos de política e falhas de mercado & 410 & -91 & 502 & 105 \\
\hline \multicolumn{5}{|c|}{ SPAM do tipo $F$} \\
\hline Preços privados & 426 & 338 & 88 & -134 \\
\hline Preços sociais & 204 & 447 & -243 & -243 \\
\hline Efeitos de política e falhas de mercado & 222 & -109 & 331 & 109 \\
\hline
\end{tabular}


Para os SPAM do tipo A, representativos das grandes explorações agroflorestais de pastagens extensivas das zonas interiores com baixa precipitação, o Resultado Líquido (RL) a preços privados é de $67 € /$ ha. Este resultado é superior aos custos sociais, estimados em $41 € /$ ha. Quando se consideram apenas as ajudas ao desenvolvimento rural do segundo pilar da PAC, o RL baixa para $16 € /$ ha. Na análise a preços sociais, o RL é negativo, indicando que os proveitos gerados pelos SPAM do tipo A numa economia liberalizada não são suficientes para remunerar todos os seus factores de produção.

Nos SPAM do tipo B, correspondentes às pequenas e médias explorações agroflorestais de pastagens e forragens das zonas interiores com baixa precipitação e com fraco florestal, o RL a preços privados é de $589 € /$ ha e é de $216 € /$ ha se considerar apenas os efeitos das políticas de desenvolvimento rural. Estes resultados superam largamente os custos sociais, avaliados em $100 € /$ ha. Na análise social, o RL também apresenta um valor positivo (100 €/ha). Os resultados permitem concluir que os SPAM do tipo B geram proveitos suficientes para fazer face a todos os seus custos, sem necessidade de transferências de rendimento das políticas públicas.

Para os SPAM do tipo C, que retratam as pequenas explorações agroflorestais das zonas litorais de boa precipitação com montado denso de azinho e de sobro, o RL a preços privados é de $514 € /$ ha e é de $374 €$ /ha tendo em conta apenas as políticas de desenvolvimento rural. Esses resultados ultrapassam claramente o custo social dos factores $(283 € / \mathrm{ha})$, sendo o RL a preços sociais $45 € /$ ha. Portanto, estes SPAM, ao retribuírem adequadamente todos os factores de produção sem o efeito das políticas públicas, são sustentáveis em termos económicos.

Nos SPAM do tipo $\mathrm{D}$, que dizem respeito às médias e grandes explorações agro-florestais das zonas elevadas interiores de boa precipitação com coberto florestal disperso principalmente de azinho, quando se considera o efeito global das políticas públicas a preços privados, o RLé de $79 € /$ ha. Este valor excede o custo social dos factores em $10 € /$ ha, mas, se mantiver apenas as políticas de desenvolvimento rural, o $\mathrm{RL}$ passa a ter um valor negativo (-50 €/ha). Estes SPAM geraram proveitos suficientes para remunerar adequadamente todos os factores de produção face às políticas institucionais em vigor, mas apresentam uma rentabilidade negativa, quando se considera apenas as políticas de desenvolvimento rural. A sua competitividade está principalmente 
associada às receitas provenientes das ajudas recebidas por via das políticas inseridas no primeiro pilar da PAC.

Com um RL a preços privados de $202 € /$ ha, os SPAM do tipo E, que incluem as pequenas explorações agro-florestais das zonas interiores próximas do litoral, com importantes manchas de sobro denso, no actual contexto de política agrícola, remuneram todos os factores, incluindo o seu custo de oportunidade. Quando se isolam os efeitos das políticas de desenvolvimento rural, o RL não só é inferior aos $91 € /$ ha estimados para os custos sociais, como é negativo (-195€/ha). Com um contributo efectivo negativo para o crescimento económico em geral, a viabilidade e a competitividade são asseguradas pelos apoios à produção e ao rendimento inseridos no primeiro pilar da PAC.

No actual contexto de políticas públicas de apoio ao sector, obtém-se para os SPAM do tipo F, que representam as pequenas e médias explorações agro-florestais de cereais e pastagens das zonas interiores com baixa precipitação, um RL de $88 € /$ ha, que é inferior aos $109 € /$ ha estimados para os custos sociais. Neste caso, os proveitos cobrem os custos reais de produção, mas não remuneram o custo de oportunidade dos recursos. Quando se isola o efeito das políticas de desenvolvimento rural, o RL assume um valor negativo (-134 €/ha).

Para facilitar a interpretação dos resultados adoptou-se a seguinte classificação dos SPAM em função dos níveis de RL e dos efeitos das medidas de política agrícola: competitivos e eficientes - o RL a preços privados e a preços sociais é positivo; competitivos e subsídio dependentes - o RL a preços sociais é negativo e o RL a preços privados é positivo e superior ao custo do social dos recursos, mas é inferior a estes quando se avaliam as políticas de desenvolvimento rural com impactos ambientais ou territoriais; competitivos e ambientalmente sustentáveis - o RL a preços sociais é negativo e o RL a preços privados é positivo e superior ao custo social dos recursos quando se avalia isoladamente as políticas de desenvolvimento rural; viáveis e subsídio dependentes - o RL a preços sociais é negativo e o RL a preços privados é positivo mas inferior ao custo social dos recursos, sendo também negativo quando se incorporam apenas as políticas de desenvolvimento rural; viáveis e ambientalmente sustentáveis - o RL a preços sociais é negativo e o RL a preços privados é positivo, mas inferior ao custo social dos recursos quando se consideram apenas as políticas de desenvolvimento rural; e economicamente inviáveis - o RL é negativo tanto a preços sociais, como a preços privados. 
Na Tabela 5, apresenta-se a classificação dos SPAM que traduz em termos das condições de competitividade e sustentabilidade os resultados da PAM apresentados anteriormente na Tabela 4.

Entre os SPAM competitivos e eficientes, encontram-se os do tipo B e do tipo C. Estes SPAM mantêm-se competitivos mesmo sem o efeito das políticas institucionais de transferência de rendimento, tendo capacidade para concorrer no mercado internacional e contribuir de modo eficiente para o crescimento do sector agro-florestal e da economia de um modo geral.

Nos SPAM competitivos e subsídio dependentes, inserem-se os SPAM dos tipos A, D e E. Neste caso, a competitividade é mantida principalmente por meio dos subsídios directos à produção e ao rendimento, pelo que sua manutenção a prazo poderá estar ameaçada com a evolução da PAC, sendo desejável a sua reconversão estrutural em SPAM competitivos e ambientalmente sustentáveis ou, mas menos provável, em SPAM competitivos e eficientes.

Tabela 5. Classificação dos SPAM segundo as condições de competitividade

Modelos Sócioeconómicos de Exploração do Ecossistema Montado (SPAM)

\begin{tabular}{ll}
\hline & $\begin{array}{l}\text { Tipo B, médias e pequenas explorações agro-florestais de } \\
\text { pastagens e forragens com bovinos das zonas interiores } \\
\text { Competitivos e eficientes } \\
\text { comaixa precipitação; } \\
\text { Tipo C, pequenas explorações agro-florestais de vinha, } \\
\text { olival e forragens-pastagens com bovinos, ovinos e suínos } \\
\text { das zonas litorais com boa precipitação; }\end{array}$ \\
\hline
\end{tabular}

Tipo A, grandes explorações agro-florestais de pastagens extensivas com bovinos e suínos das zonas interiores com baixa precipitação;

Competitivos e subsídio dependentes

Tipo D, médias e grandes explorações agro-florestais de forragens e pastagens com bovinos e suínos das zonas elevadas interiores com boa precipitação;

Tipo E, pequenas explorações agro-florestais de cereais-pastagens com bovinos das zonas interiores próximas do litoral com boas precipitações;

$\begin{array}{ll}\text { Viáveis e subsídio } & \text { Tipo F, pequenas e médias explorações agro-florestais de } \\ \text { dependentes } & \text { cereais e pastagens com bovinos das zonas interiores com } \\ \text { baixa precipitação; }\end{array}$

Fonte: Tabela 2. 
Finalmente, o grupo dos SPAM viáveis e subsídio dependentes, que são representados pelos SPAM do tipo F. Estes SPAM não são competitivos, porque não remuneram os recursos ao nível do seu custo de oportunidade e a sua viabilidade está associada aos subsídios de apoio directo à produção e ao rendimento da PAC. Sendo mais vulneráveis do que os SPAM competitivos e subsídio dependentes, a sua manutenção a prazo depende da capacidade de ajustamento, nomeadamente, de reduzir custos e de valorizar as suas produções.

Na Tabela 6, apresenta-se a agregação dos resultados da PAM, para o total do Alentejo em função do número de explorações e da sua superfície.

Tabela 6. Resultados agregados da PAM no Alentejo

\begin{tabular}{lcc}
\hline SPAM & Explorações (\%) & Superfície Total (\%) \\
\hline Competitivos e eficientes & 40 & 38,6 \\
Competitiv.e subsídio dependentes & 50 & 57,3 \\
Viáveis e subsídio dependentes & 10 & 4,1 \\
\hline
\end{tabular}

Fonte: Tabela 3 e em Anexo Tabela A2.

Os SPAM competitivos e subsídio dependentes são os predominantes no Alentejo, representando metade das explorações agroflorestais da Região e $60 \%$ da sua superfície. Em segundo lugar, aparecem os SPAM competitivos e eficientes, com cerca de $40 \%$ das explorações agro-florestais e da respectiva superfície. Por último, surgem os SPAM viáveis e subsídio dependentes, que contam com $10 \%$ das explorações agro-florestais e com $4,1 \%$ da sua superfície total. Portanto, a maior parte das explorações agro-florestais do Alentejo faz depender a sua competitividade das ajudas institucionais de apoio directo à produção e ao rendimento, inseridas no primeiro pilar da PAC. No entanto, é de salientar que uma grande parte é sustentável do ponto de vista económico e tem um contributo efectivo para o crescimento económico, mesmo sem o apoio das políticas públicas de transferência de rendimento.

\section{Conclusão}

A avaliação da competitividade da agricultura do Alentejo no âmbito do ecossistema Montado baseou-se na identificação dos SPAM representativos e na elaboração de Matrizes de Análise Política (PAM). Os resultados obtidos permitem concluir que a competitividade da maior 
parte dos SPAM depende das ajudas institucionais de apoio directo à produção e ao rendimento, inseridas no primeiro pilar da PAC.

Apenas os SPAM relativos às pequenas e médias explorações de pastagens e forragens das zonas interiores de baixa precipitação e às pequenas explorações das zonas litorais com boa precipitação e montado denso, que no total representam $40 \%$ das explorações agro-florestais e $38,6 \%$ da superfície, são competitivos e eficientes, apresentando resultados líquidos positivos tanto em termos sociais como em termos privados.

Os SPAM das grandes explorações de pastagens extensivas com bovinos e suínos das zonas interiores com baixa precipitação e das zonas elevadas interiores com boa precipitação, assim como as pequenas exploraçóes de cereais pastagens com bovinos das zonas interiores próximas do litoral, que representam $50 \%$ do total das explorações e $57,3 \%$ da superfície agro-florestal do Alentejo, são competitivas, na medida em que apresentam resultados líquidos positivos a preços privados que permitem remunerar os custos de oportunidades dos factores próprios. Essa competitividade, contudo, apenas é assegurada devido às ajudas à produção ao rendimento inseridas no primeiro pilar da PAC.

Por último, as pequenas e médias explorações de cereais e pastagens com bovinos das zonas interiores com baixa precipitação, que abrangem $10 \%$ das explorações e $4 \%$ da superfície, são classificadas como viáveis e subsídio dependentes. Estas explorações, apesar de apresentarem resultados líquidos positivos a preços privados, não conseguem remunerar adequadamente o custo de oportunidade dos factores primário e a sua viabilidade decorre apenas das transferências institucionais de rendimento do primeiro pilar da PAC.

No futuro, seria desejável que os SPAM classificados como competitivos passassem a beneficiar mais das ajudas do segundo pilar da PAC em detrimento do primeiro pilar, o que implicaria ajustamentos nas tecnologias e nas opções produtivas numa perspectiva territorial de desenvolvimento rural e de preservação dos recursos ambientais. Esses ajustamentos não serão difíceis de alcançar, na medida em que na maior parte dos casos, a produção agro-florestal já está orientada para sistemas de produção extensivos, que beneficiam de custos de produção relativamente baixos, de um potencial de valorização de produtos com qualidade reconhecida nos mercados e da utilização de tecnologias de 
produção agroflorestal que contribuem para a manutenção das condições ambientais do ecossistema.

\section{Referências Bibliográficas}

ABREU, J. V. Sheep as a competitive livestock enterprise in Missouri. Tese (Mestrado). Universidade de Missouri, Columbia, 1987.

AVILLEZ, F. et QUEIROZ, A. A competitividade da beterraba sacarina no contexto da agricultura dos vales do Tejo e Sorrais. Revista de Ciências Agrárias, vol. n.ํㅜ: 5-21, 1987.

AVILLEZ, F. et CARRILHO, A. Situação actual e competitividade futura das explorações agrícolas portuguesas. Évora, Actas do Seminário EEC Agricultural Markets and Policy, 19.1-19.44, 1988.

BAYSAN, T. Resource shifts under tariff liberazation and Turkey's comparative advantage in agriculture. European Review of Agricultural Economics, 11 (3). 1984.

BUREAU, J. et BUTUAULT, J.P. Competitivité des agricultures et advantages nationaux de prix dans la CEE : différentiels de productivité et PPA spécifiques sur la base des coûts de production des grands produits agricoles. Hague, Vith European Congress of Agricultural Economists, pp.93-106, 1990.

JARABA, C. et THOMPSON, R. Agricultural comparative advantage under international price incertainty: thge case of Senegal. American Journal of Agricultural Economics, 188-198, 1980.

FOX, R. Extensive farming in Alentejo in Portuguese Agriculture in Transition. Ithaca, USA, Scott R. Pearson Eds, Cornell University Press, 1987.

MARQUES, C. A. F. Portuguese entrance into the european community: implications for dryland agriculture in the alentejo region. 274 p. Tese (Doutorado). Purdue University. West Lafayette, U.S.A., 1988.

MARQUES, C.;MARTINS, M.B.; et LUCAS, R. A reforma da PAC e a competitividade da agricultura regional. Feira do Alentejo/95- 12 ${ }^{\underline{a}}$ Ovibeja, Beja, 23 de Março, 1995. 
MARTIN, F. P. Food security and comparative advantage in Senegal: a micro-macro approach. Tese(Doutorado), Michigan State University, USA, 1989.

MATTAS, K. Competitiveness of EC'S agriculture an intra-EC analysis. Hague, Vith European Congress of Agricultural Economists, pp. 108-120, 1990.

MAZA, M. T.; OLAIZOLA; MANRIQUE et HAMROUNI, S. Influence of production and economic factors on the comparative advantages of sheep production systems in the EEC, Dep. Agricultura y Economia Agraria, Universidad de Zaragoza, Zaragoza, 1992.

PEARSON, S. et MEYER, R. Comparative advantage among African coffee producers. American Journal of Agricultural Economics, 56: 310-313, 1974.

PEARSON, S.; AVILLEZ, F.; BENTLEY, J. W.; FINAN, T.; FOX, R.; JOSLING, T.; LONGWORTHY, MONKE, E. et TANGERMANN, S. Portuguese Agriculture in Transition. Nova Iorque and Ithaca, Coirnell University Press, 1987.

PEARSON, S. et MONKE, E. The Policy Analysis Matrix for Agricultural Development. 279 p. Ithaca and London, Cornell University Press, 1989.

SANTANA, E. A produção leiteira açoreana face à concorrência internacional: as vantagens comparativas. Tese (Doutorado), Universidade dos Açores, Angra do Heroísmo, 1986.

LUCAS, M. A competitividade da produção de borrego no Alentejo. Tese (Doutorado), Universidade de Évora, Évora, Portugal, 1995.

LUCAS, M.; FRAGOSO, R. et COELHO, L. Caracterização Sócioeconómica da Região Alentejo. Relatório da 2a fase do Projecto Interreg Desarollo de un sistema de información para la gestión ambiental y económica del ecosistema dehesa/montado en Extremadura y Alentejo, 2005.

VENTURINI, L. Teorie del commercio internazionale e determinanti della competitivitá: un quadro conceptuale per l'analisi degli scambi agro-alimentari, Rivista di Economia Agraria, vol. 44 (1): 3-24, 1989. 
